PDFlib PLOP: PDF Linearization, Optimization, Protection

Page inserted by evaluation version www.pdflib.com - sales@pdflib.com 


\title{
Enhancement of Humoral Immunity by Interleukin-12
}

\author{
DENNIS W. METZGER,, J. MATTHEW BUCHANAN, \\ JOHN T. COLLINS, ${ }^{b}$ TERRY L. LESTER, ${ }^{a}$ \\ KRISTIN S. MURRAY," VICTOR H. VAN CLEAVE, \\ LAURA A. VOGEL, ${ }^{a}$ AND WESLEY A. DUNNICK ${ }^{b}$ \\ "Department of Microbiology \\ Medical College of Ohio \\ 3000 Arlington Avenue \\ Toledo, Ohio 43699-0008 \\ ${ }^{b}$ Department of Microbiology and Immunology \\ University of Michigan Medical School \\ 1301 E. Catherine \\ Ann Arbor, Michigan 48109-0620 \\ 'Preclinical Research \\ Genetics Institute \\ One Burtt Road \\ Andover, Massachusetts 01810
}

\begin{abstract}
It is being increasingly recognized that interleukin (IL)-12 has profound influences in regulating not only cellular immunity, but humoral immunity as well. The precise effects of IL-12 on B-cell activity and the mechanism(s) responsible for them, however, remain unclear. Some groups have previously reported that the primary effect of IL-12 on B cells is suppression of Ig production, ${ }^{1,2}$ particularly of Th2associated isotypes (IgG1 and IgE in the mouse). Conversely, we and others have found that IL-12 administration enhances production of nearly all Ig isotypes.,4 Furthermore, the role of interferon (IFN)- $\gamma$ in mediating these effects is uncertain, since in many cases, the ability of IL-12 to influence humoral immunity is either not affected ${ }^{1,5}$ or incompletely inhibited ${ }^{2}$ by anti-IFN- $\gamma$ antibodies. In this paper, we describe our studies, which deal with the ability of IL-12 to modify in vivo and in vitro activities of B-cell subsets. The results of these experiments have led to us to formulate a hypothesis that explains the apparent paradoxical findings regarding the action of IL- 12 on $B$ cells.
\end{abstract}

\section{IL-12 AS AN ADJUVANT FOR HUMORAL IMMUNITY}

To initially examine the influence of IL-12 on humoral immunity, we used hen egg white lysozyme (HEL) as a model antigen. HEL is structurally and immunologically well defined and has the unusual property of inducing almost exclusively Th2-associated IgGl production in mice, even during primary responses. Under normal conditions, there is almost no contribution by the Th1associated isotype, IgG2a, although significant amounts of IgG2a anti-HEL antibody can be induced by certain manipulations. ${ }^{6,7} \mathrm{We}$ predicted, therefore, that administration of IL-12 during induction of an anti-HEL response would activate 


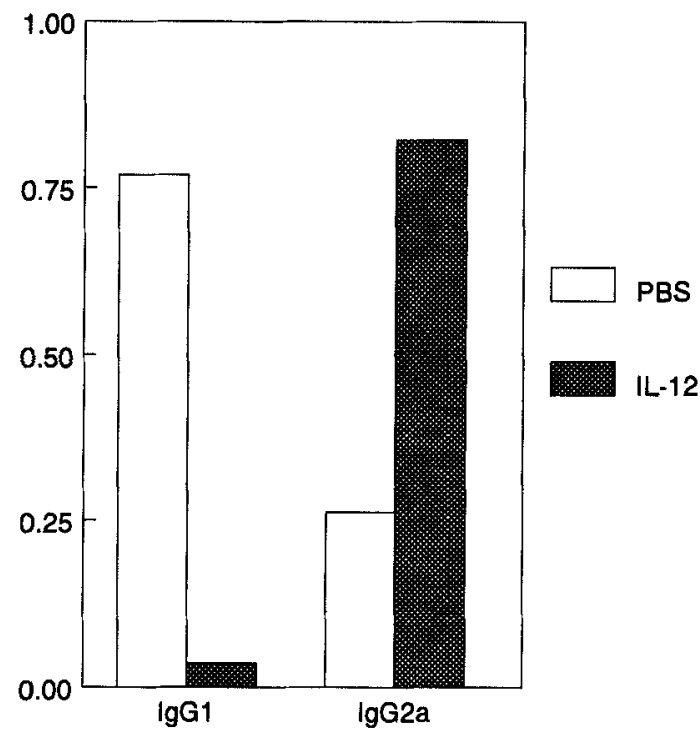

FIGURE 1. Suppression of IgG1 and enhancement of IgG2a anti-HEL levels in the early (day 7) response of BALB/c mice to HEL. Mice were treated with either $1 \mu \mathrm{g}$ IL- 12 or PBS on days $-1,0$, and 1 , followed by immunization with $100 \mu \mathrm{g} \mathrm{HEL}$ on day 0 . They were then bled on day 7 and tested for anti-HEL antibody by ELISA using HEL-coated microtiter plates. Each bar represents the mean OD of 4 mice/group.

Thl cells and have significant effects on the isotype distribution of the secreted antibodies. BALB/c mice were given three injections of PBS or IL-12 at the time of initial HEL immunization. Seven days later, it was found that IL-12 caused significant suppression of IgG1 anti-HEL production and enhancement of IgG2a production compared to control animals (FIG. 1). Enhancement was long-lasting and still evident by 28 days after priming, while the IgG1 suppression was lost by this time, and, in fact, IgG 1 levels were actually found to be somewhat increased on day 28 (FIG. 2). These effects were amplified by administering a second dose of IL-12 on day 28 (FIGS. 3 and 4). Furthermore, delaying cytokine treatment until the typical IgG1 anti-HEL response had already been established still led to significant elevation of both IgG2a (FIG. 3) and IgG1 (FIG. 4) antibody levels.

We also examined the ability of IL-12 to alter antibody responses to the phosphorylcholine (PC) hapten. PC, unlike HEL, induces production of IgM, IgG1, IgG2a, IgG2b, IgG3, and IgA antibodies, offering the opportunity to examine the effects of IL-12 on expression of various isotypes. Measurement of IgG1 and IgG2a antibodies after IL-12 treatment and immunization with PC conjugated with keyhole limpet hemocyanin (KLH) yielded results that were nearly superimposable over those obtained in the response to HEL (FIG. 5). Seven days after immunization, IL-12-treated mice showed substantially higher levels of IgG2a anti-PC antibodies and lower levels of IgG1 antibodies compared to control mice injected only with PBS. By day 17 , both IgG1 and $\operatorname{IgG} 2 \mathrm{a}$ antibody levels were enhanced in IL-12-treated mice. With regard to expression of other anti-PC isotypes, there appeared to be a suppression of $\operatorname{IgM}$ and $\operatorname{IgG} 3$ antibodies at day 7 after IL-12 
treatment, but this suppression disappeared by day 17 and, in fact, enhancement was observed at this time point (FIG. 6). Levels of serum IgA anti-PC antibodies were similar to controls at day 7, but were somewhat greater in IL-12-treated mice at day 17 (FIG. 6). Very little IgG2b was produced by any mouse at either timepoint (data not shown). To ensure that the reactivity observed was specific for PC, sera were also tested for binding to bovine serum albumin (BSA)-coated wells. Binding to BSA was not observed in either experimental or control sets of mice.

A kintetic study of the early response to HEL was next performed to determine whether the two main effects of IL-12, that is, suppression of Th2-like responses (IgG1) and enhancement of Th1-like responses (IgG2a), were correlated with respect to time. It was found that they were in fact not correlated and that induction of IgG2a expression actually correlated with increasing amounts of IgG1 (FIG. 7). This finding explains why some investigators have observed IgG1 suppression as the dominant effect of IL-12 while others have reported mostly isotype enhancement-IgG1 suppression occurs only very early in the response and then produc-

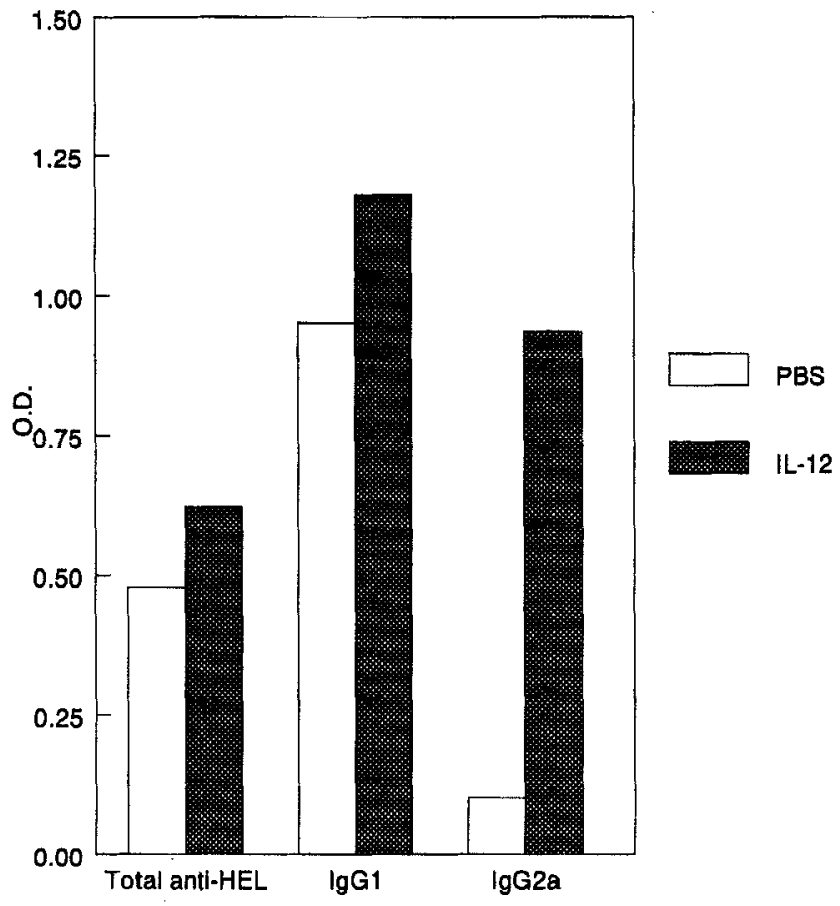

FIGURE 2. Effect of IL-12 on day 28 anti-HEL serum antibody levels. Mice were treated with IL-12 or PBS on days $-1,0$, and 1, immunized with HEL on day 0 , and then boosted weekly with HEL thereafter. Antibody levels were determined by ELISA using HEL-coated microtiter plates. For determination of total anti-HEL levels, a 1:1000 serum dilution was used, for determination of IgG1 anti-HEL levels, a $1: 8000$ serum dilution was used, and for determination of IgG2a anti-HEL levels, a $1: 640$ dilution was used. Each bar represents the mean OD of 4 mice/group. 


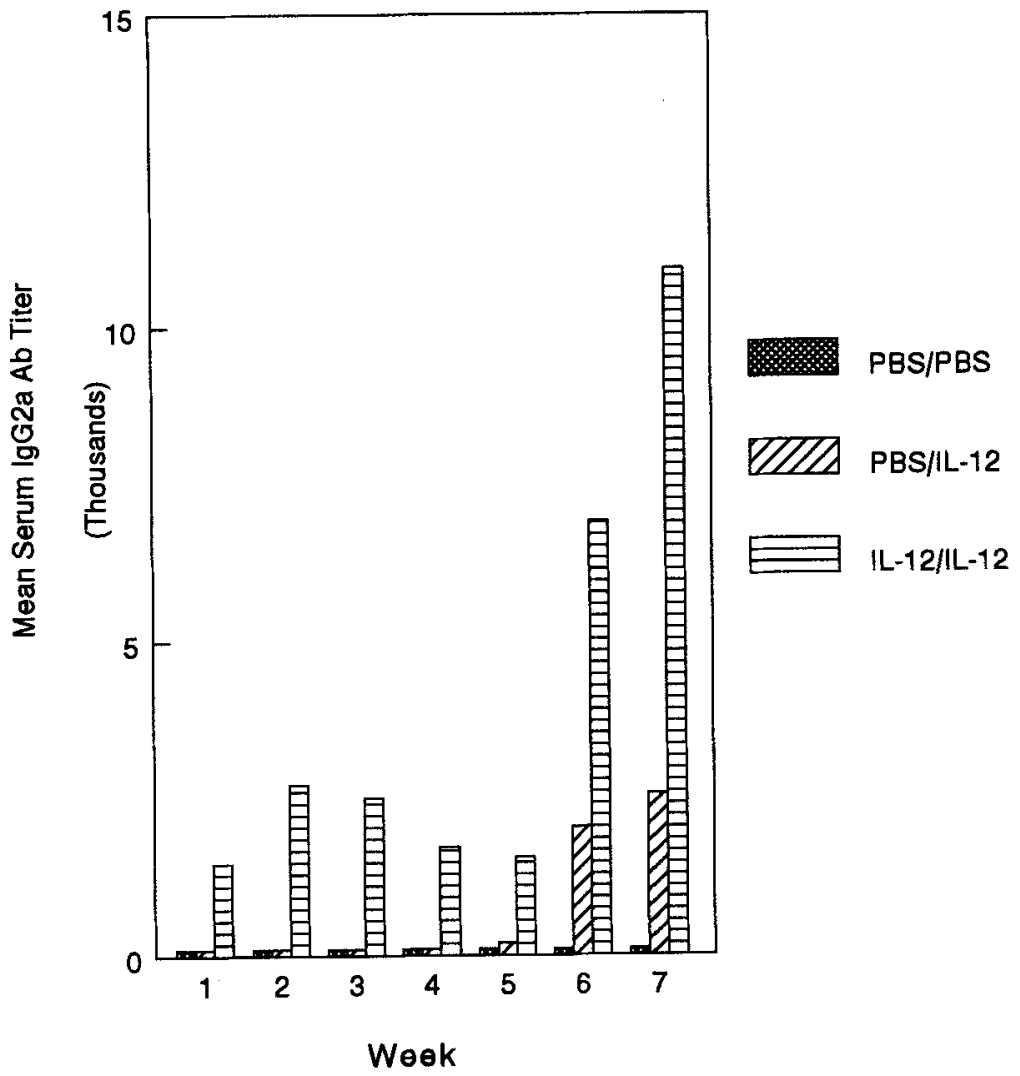

FIGURE 3. Effects of repeated or delayed IL-12 treatment of IgG2a anti-HEL responses. Mice were treated with either IL-12 or PBS on days -1 through 1 and 28 through 30 . PBS/PBS mice received PBS and IL-12/IL-12 mice received IL-12 over both treatment periods, while PBS/IL-12 mice first received PBS on days -1 through 1 and IL-12 on days 28 through 30 . Serum antibody titers represent the reciprocal serum dilution corresponding to $50 \%$ maximum binding in each individual assay. Each bar represents the mean OD of 4 mice/group.

tion of IgG2a and other isotypes (including IgG1) is stimulated. The results also suggest that independent mechanisms are responsible for the two effects.

\section{MECHANISMS FOR THE ACTION OF IL-12 ON ANTIBODY RESPONSES}

The effects of IL-12 on specific in vivo antibody responses can be mimicked in vitro using lipopolysaccharide (LPS) as a polyclonal B-cell activator. In initial experiments, spleen cells from normal BALB/c mice were cultured for 8 days 
with $3 \mu \mathrm{g} / \mathrm{ml}$ of LPS and $5 \mathrm{ng} / \mathrm{ml}$ of murine rIL-12. After culture, the supernatant fluids were tested for total IgG1 and IgG2a levels in isotype-specific ELISA assays. It was found that, similar to our in vivo results, levels of total IgG1 induced by LPS were slightly, if at all, suppressed in cultures receiving IL-12, but IgG2a production was strongly enhanced (FIG. 8). Interestingly, nearly identical results were obtained with B-cell-enriched preparations that were obtained by depletion of $T$ cells before initiation of culture (data not shown). However, when both $T$ cells and NK cells were depleted, IgG1 suppression and IgG2a enhancement were lost (FIG. 8). These results suggest that IL-12-activated NK cells are sufficient to mediate the cytokine's effects on Ig expression. Snapper et al. ${ }^{8}$ have also reported that NK cell-derived cytokines have important influences on $\mathrm{Ig}$ production.

Our findings demonstrate that IgG2a enhancement is the predominant and longer lasting effect of IL-12, while IgG1 suppression is variable and shortlived. We next investigated whether IL-12 selectively expands cells already secreting IgG2a or recruits new B cells by inducing isotype switching to $\gamma 2 a$

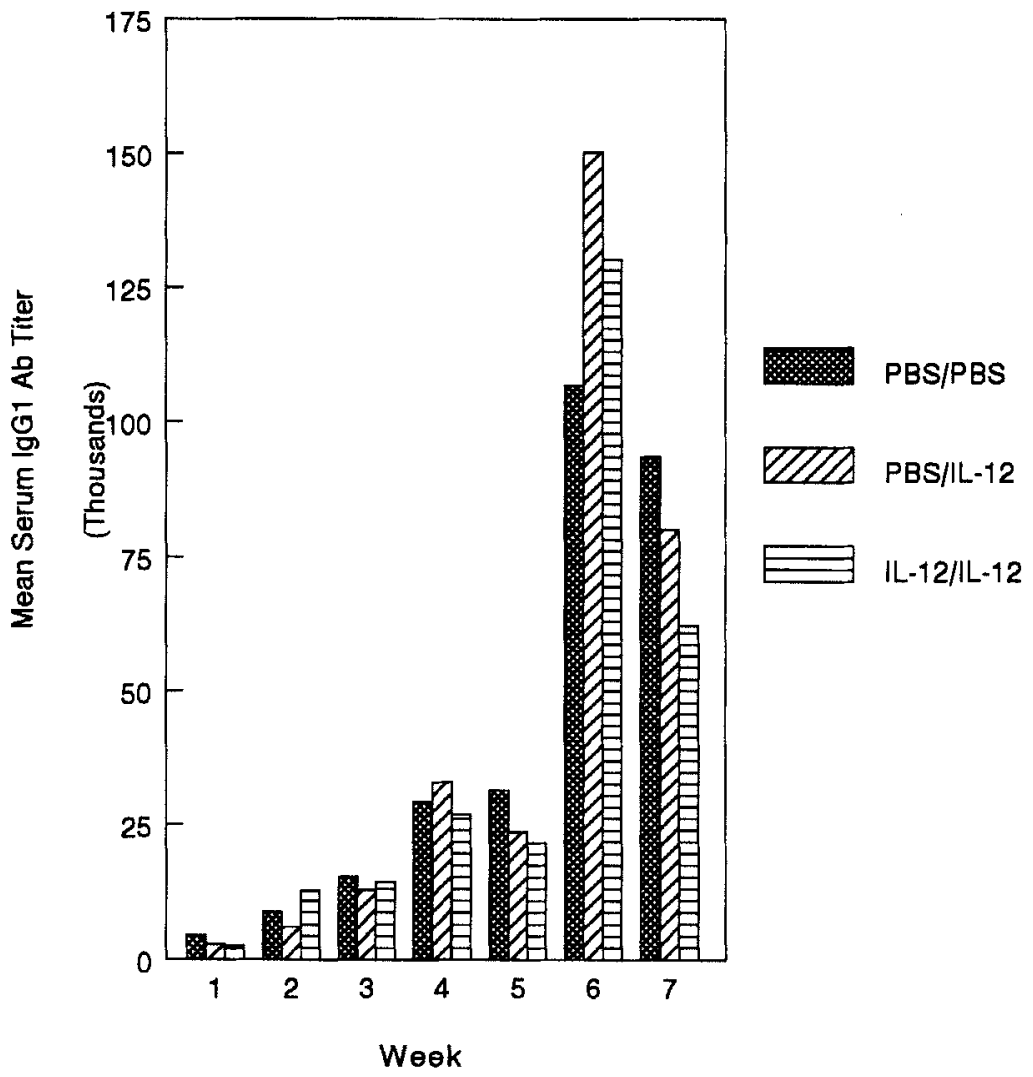

FIGURE 4. Effects of repeated or delayed IL-12 treatment on IgG1 anti-HEL responses. Mice were treated as described in FIGURE 3. Each bar represents the mean OD of 4 mice/group. 
Day 7

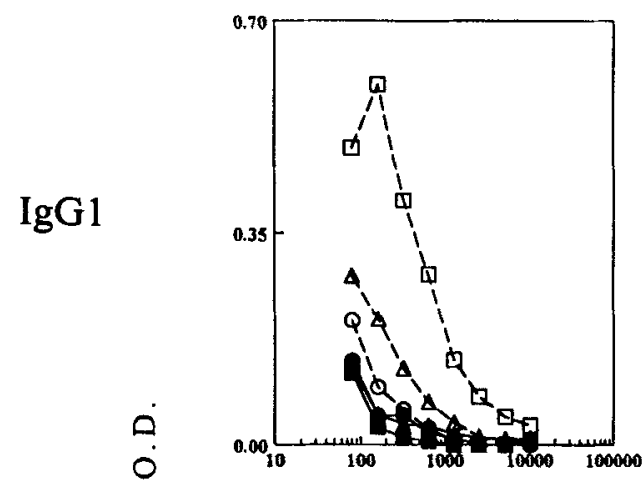

$\operatorname{IgG} 2 \mathrm{a}$

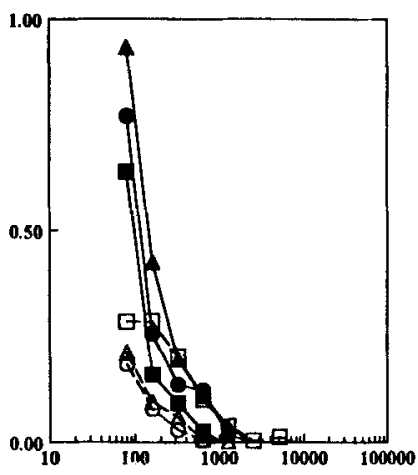

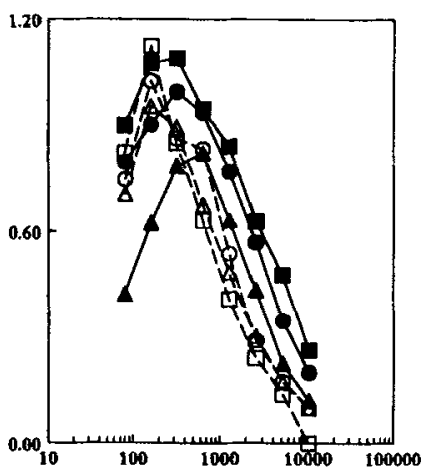

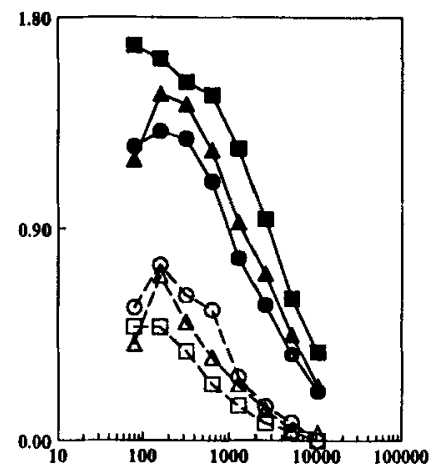

Day 17

\section{Reciprocal Serum Dilution}

FIGURE 5. Effect of IL-12 treatment on IgG1 and IgG2a anti-PC responses. Day 7 (left column) and day 17 (right column) serum anti-PC responses were measured in isotypespecific ELISA assays using PC-BSA-coated wells after injection of IL-12 (closed symbols) or PBS (open symbols) on days $-2,-1$, and 0 , and PC-KLH on day 0 . Each line represents binding of serum from an individual mouse.

heavy chains. This question was first examined by performing limiting dilution cloning of LPS-stimulated spleen cells essentially as described by Layton et $a l .^{9}$ In the case of $\mathrm{T}$ cells, similar precursor analyses have provided evidence that IL-12 has a direct differentiative effect on all $\mathrm{T}$ cells, priming them for high IFN- $\gamma$ production upon subsequent stimulation. ${ }^{10}$ To examine the effects of IL-12 on B cells, spleen cells from normal BALB/c mice were diluted in medium containing LPS \pm IL-12, mixed with a constant amount of irrelevant "filler" cells (syngeneic thymocytes that were depleted of B cells by anti-Ig panning), and cultured at limiting concentrations in microtiter plates for eight 
days. The percentages of IgG2a-secreting cultures were then determined by assaying supernatant fluids from individual wells for the presence of IgG2a. It was found that IL-12 led to an approximate twofold increase in numbers of IgG2a-containing wells, suggesting that IL-12 does in fact lead to new B-cell recruitment. This recruitment was dependent on IFN- $\gamma$ since addition of antiIFN- $\gamma$ antibody to the cells at the initiation of culture led to a dramatically decreased frequency in IgG2a secreting cultures (data not shown).

We further assessed the ability of IL-12 to induce isotype switching in LPSstimulated cells by testing for the presence of germline $\gamma 2$ a transcripts. It has

\section{Day 7}
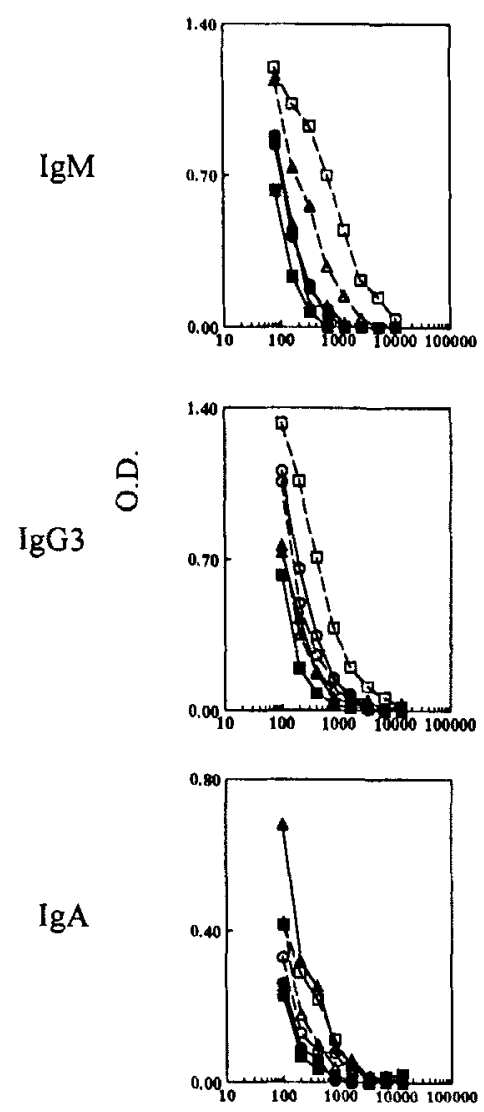

Day 17
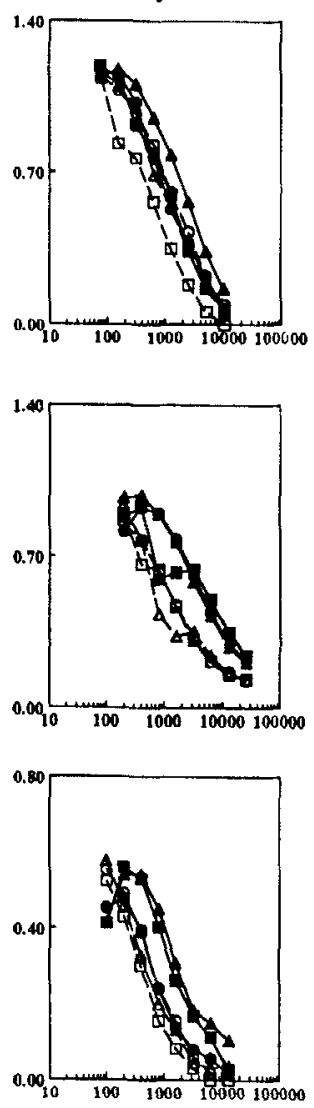

Reciprocal Serum Dilution

FIGURE 6. Effect of IL-12 treatment of IgM, IgG3, and IgA anti-PC responses. Day 7 (left column) and day 17 (right column) serum anti-PC responses were measured in isotypespecific ELISA assays using PC-BSA-coated wells after injection of IL-12 (closed symbols) or PBS (open symbols) on days $-2,-1$, and 0 , and PC-KLH on day 0 . Each line represents binding of serum from an individual mouse. 


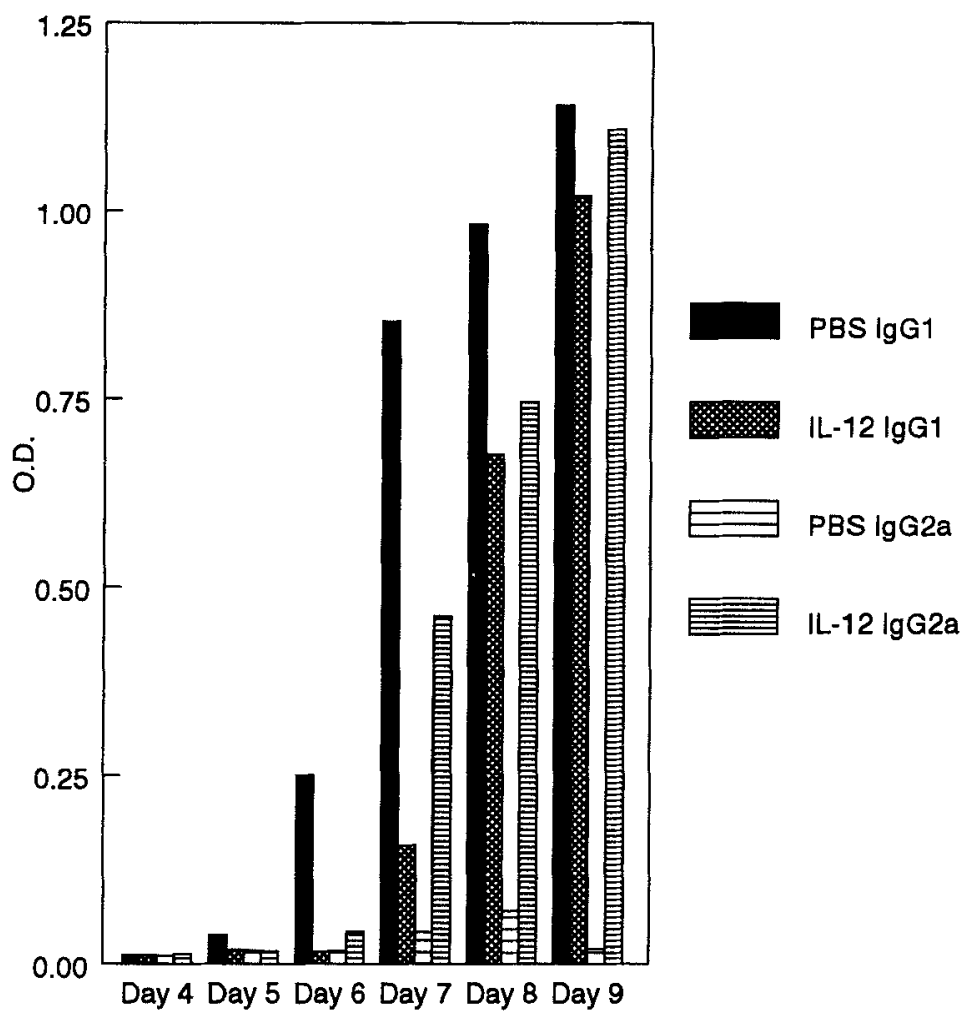

FIGURE 7. Kinetics of the in vivo IgGI and IgG2a primary responses to HEL. Mice were treated daily with either IL-12 or PBS on days -1 through 4 and immunized with HEL on day 0 . Serum antibody levels were determined on days 4 through 9 using 1:10 dilutions of sera. Each bar represents the mean OD of 3 mice/group.

been shown that before recombination, the targeted heavy chain is transcribed in a germline configuration, and such transcripts are induced by the same cytokines that lead to switch recombination. ${ }^{11}$ For our experiments, mouse spleen cells were cultured with LPS \pm IL- 12 for 3 days and germline $\gamma 2 a$ transcripts were detected by $S 1$ nuclease protection analysis using a probe specific for the $I \gamma 2 \mathrm{a}$ exon, as previously described for detection of IFN- $\gamma$-induced germline $\gamma 2$ a transcripts. ${ }^{12}$ As shown in TABLE 1, incubation of cells with either IFN- $\gamma$ or IL-12 led to production of $\gamma 2 \mathrm{a}$ germline transcripts in whole spleen cell cultures stimulated with LPS. Induction of germline transcripts by IL-12 was specific for IgG2a, with no effect on $\gamma 1$ germline transcript expression, although IL-4 clearly stimulated $\gamma 1$ switch recombination. It was found that IL-12 also induced a small but significant amount of $\gamma 2 \mathrm{a}$ germline transcript production in purified B cells that had been panned on anti-Ig plates. Addition of anti-IFN- $\gamma \mathrm{mAb}$ to the cultures greatly reduced or abolished production of the $\gamma 2 \mathrm{a}$ transcripts. Finally, depletion of both T cells and NK cells prevented IL-12-induced enhancement of $\gamma 2$ a germline transcript expression. Taken together, the results suggest that IL-12 acts on LPS- 
activated spleen cells in vitro to cause IFN- $\gamma$-dependent isotype switching. Amounts of IFN- $\gamma$ sufficient to induce $\gamma 2$ a switching can be produced by either $\mathrm{T}$ cells or NK cells, and there are apparently enough of these cells contaminating panned B-cell preparations to mediate this effect. Interestingly, the IFN- $\gamma$-dependence of in vitro $\gamma 2$ a isotype switching differs from our in vivo studies on IL-12's ability to enhance IgG2a antibody responses. We found that in vivo administration of anti-IFN- $\gamma$ antibody reversed the IL-12-mediated suppression of IgG1 antiHEL levels that was observed on day 7 of the response, but had no effect on IgG2a enhancement. It is likely that these different results relate to factors such as the use of specific versus polyclonal B-cell stimulators and in vivo versus in vitro activation conditions.

Other experimental findings from our laboratory indicate that IL-12 is also able to increase IgG2a secretion by post-switched cells. ELISPOT analysis of IgG2a-secreting cells that were induced by exposure to IL-12 showed that, based on the side of the spots obtained, IL-12 dramatically enhanced Ig secretion by individual cells. Furthermore, when the amounts of IgG2a in limiting dilution cultures were quantitated, it was found that those positive wells that had been exposed to both LPS and IL-12 contained increased levels of IgG2a compared to positive wells from plates receiving only with LPS (FIG. 9). This enhancement of IgG2a secretion in post-switched cells was not prevented by co-incubation with anti-IFN- $\gamma \mathrm{mAb}$.

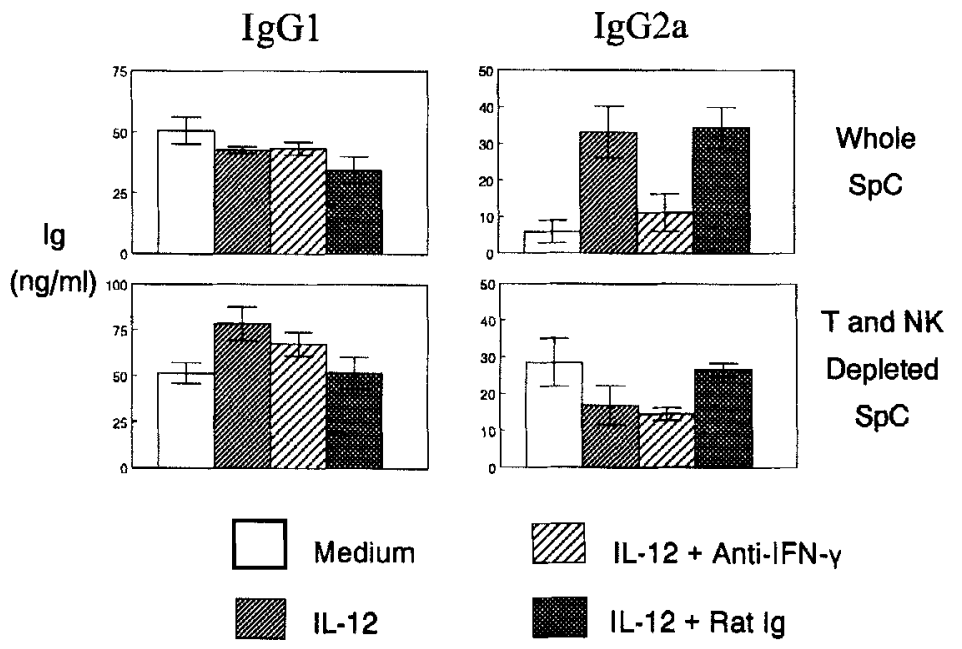

FIGURE 8. Effect of IL-12 on in vitro Ig production by LPS-stimulated spleen cells (SpC). Whole SpC (top) or T and NK cell-depleted SpC (bottom) were cultured for 8 days with $3 \mu \mathrm{g} / \mathrm{ml}$ LPS. In addition the cultures also received $5 \mathrm{ng} / \mathrm{ml} \mathrm{IL-}-12,20 \mu \mathrm{g} / \mathrm{ml} \mathrm{XMG1.2} \mathrm{anti-}$ IFN- $\gamma \mathrm{mAb}$, or $20 \mu \mathrm{g} / \mathrm{ml}$ normal rat Ig. The supernatants were then assayed for total levels of IgG1 (left) and IgG2a (right). Similar results were obtained with $50 \mathrm{ng} / \mathrm{ml}$ of IL-12. T and NK cell depletion was performed by incubation of cells with anti-Thy-1/anti-CD3/antiAsGm- 1 antibodies and rabbit complement. As assessed by flow cytometry, the percentage of $\mathrm{CD}^{+} \mathrm{T}$ cells in the unseparated and depleted SPC populations were $55 \%$ and $<2 \%$, respectively. 
TABLE 1. Expression of Germline Transcripts by Murine Spleen Cells Treated with Cytokines

\begin{tabular}{|c|c|c|c|c|}
\hline Experiment & Cells & Treatment & $\gamma 2 \mathrm{a}$ & $\gamma 1$ \\
\hline \multirow[t]{6}{*}{1} & Whole splenocytes & None & 0.8 & \\
\hline & & LPS & 1.6 & $<1.3$ \\
\hline & & LPS + IFN- $\gamma$ & 26.2 & $<1.5$ \\
\hline & & $\mathrm{LPS}+\mathrm{IL}-12$ & 27.7 & 0.8 \\
\hline & & LPS + IL-4 & 0.5 & 17.9 \\
\hline & & (tRNA) & 1.2 & 0.7 \\
\hline \multirow[t]{6}{*}{2} & Panned B cells & LPS & $<0.1$ & \\
\hline & & LPS + IFN- $\gamma+$ rat Ig & 12.2 & \\
\hline & & LPS + IFN- $\gamma+$ anti-IFN- $\gamma$ & 2.5 & \\
\hline & & $\mathrm{LPS}+\mathrm{IL}-12+$ rat $\mathrm{Ig}$ & 1.9 & \\
\hline & & LPS + IL-12 + anti-IFN- $\gamma$ & 0.1 & \\
\hline & & (tRNA) & 0.1 & \\
\hline \multirow[t]{4}{*}{3} & $\mathrm{~T}$ and $\mathrm{NK}$ cell- & LPS & 1.3 & \\
\hline & depleted spleen cells & LPS + IFN- $\gamma$ & 5.4 & \\
\hline & & $\mathrm{LPS}+\mathrm{IL}-12$ & 1.5 & \\
\hline & & (tRNA) & $<0.4$ & \\
\hline
\end{tabular}

NotE: Relative levels of germline transcripts were determined using $\mathrm{S} 1$ nuclease protection assays, total cellular RNA, and probes specific for the $y 2 \mathrm{a}$ and $\gamma 1$ germline transcripts. ${ }^{12.28}$ The resulting autoradiographs were scanned, and the film background for each band was subtracted using an adjacent, equal-sized area. The resulting value is the relative level of germline transcript expression. In those cases in which the background value was actually larger than the adjacent experimental sample, the data are reported as less than the negative value. Relative amounts of germline transcripts can only be compared within an experiment, not among experiments. "(tRNA)" refers to the amount of hybridization of probe with E. coli TRNA.

\section{SUPPRESSIVE EFFECTS OF IL-12 ON B1 CELL FUNCTION}

In contrast to its stimulating effects on conventional B-cell responses, IL-12 has a strong inhibitory influence on B1 cells. B1 cells (formerly called CD5 B cells) differ in phenotype and apparent function from conventional B (B2) cells, especially with regard to their involvement in $\mathrm{T}$-dependent antibody responses. $B 1$ cells are thought to respond primarily to $T$-independent antigens such as $\alpha(1 \rightarrow 3)$ dextran, LPS, and phosphorylcholine (PC), ${ }^{13-15}$ but they are believed not to significantly contribute to antibody responses against $\mathrm{T}$-dependent antigens. ${ }^{13,15}$ Nevertheless, B1 cells can mount antibody responses to PC-KLH ${ }^{16}$ and HEL, ${ }^{7}$ although in the latter case, their epitope recognition repertoire is severely limited. Furthermore, the T-cell-derived cytokines IL-2, IL-4, and IL-5 stimulate proliferation and differentiation of $\mathrm{B} 1$ cells, while IFN $\gamma$ inhibits $\mathrm{B} 1$ cell activity. ${ }^{17-21}$ Curiously, B1 cells are the major source of B-cell-derived IL-10, a Th2-like cytokine that suppresses Th1 cells. ${ }^{22,23}$

To determine the effects of IL-12 on B1 cells, we first measured levels of T15 idiotype in mice immunized with PC-KLH. Antibodies bearing the T15 idiotype, which account for about $90 \%$ of the normal BALB/c anti-PC response, are reported to be secreted solely by B1 cells. ${ }^{16,24}$ Thus, levels of serum T15 idiotype in immunized mice are a useful indication of B1 cell activity. Serum T15 idiotype levels were measured in both IL-12 and PBS-treated mice by ELISA. For this assay, microtiter plates were coated with the anti-TEPC 15 idiotype antibody, AB1-2, 
and the binding of TEPC 15 myeloma protein was measured in the presence of inhibitory serum. No inhibition was observed with the addition of BALB/c NMS (FIG. 10A). Sera from mice that received IL-12 showed significantly less inhibition (P value $<0.01$ by Student's $t$-test) than sera from PBS-treated mice, showing that IL-12 suppressed serum T15 idiotype expression. No differences were observed in levels of total anti-PC activity between mice receiving IL-12 or PBS (FIG. 10B), indicating that IL-12 selectively suppressed antibody production by B1 cells, which then led to compensation by conventional B cells. By day 17 , all mice appeared to have similar levels of serum T15 idiotype; however, mice receiving IL-12 had higher levels of total anti-PC antibodies (data not shown). Therefore, the fraction of anti-PC antibodies bearing the T15 idiotype was lower in mice receiving IL-12 compared to control-treated mice.

These initial observations were followed by direct measurement of B1 cell levels in vivo. This was accomplished by performing flow cytometry on the peritoneal cells, a rich source of B1 cells, in mice injected with PC-KLH and IL-12. The results revealed striking differences in numbers of $\mathrm{IgM}^{+}$peritoneal B lymphocytes early after IL- 12 treatment. On day 7 after treatment, IL-12 and PBS-treated mice contained $4 \%$ and $35 \%$ peritoneal B cells, respectively. Detailed phenotypic analyses demonstrated loss of both $\mathrm{B} 1$ and $\mathrm{B} 2$ cells in the peritoneum. The B cells only began to reappear on day 30 and then reached normal levels by day 45 . Nevertheless, at this time point, only B2 cell numbers were restored, and B1 cell levels were still severely suppressed. This effect was localized to the peritoneum since levels of splenic B cells, consisting almost entirely of B2 cells, remained normal throughout the period of observation. Furthermore, it was dependent upon

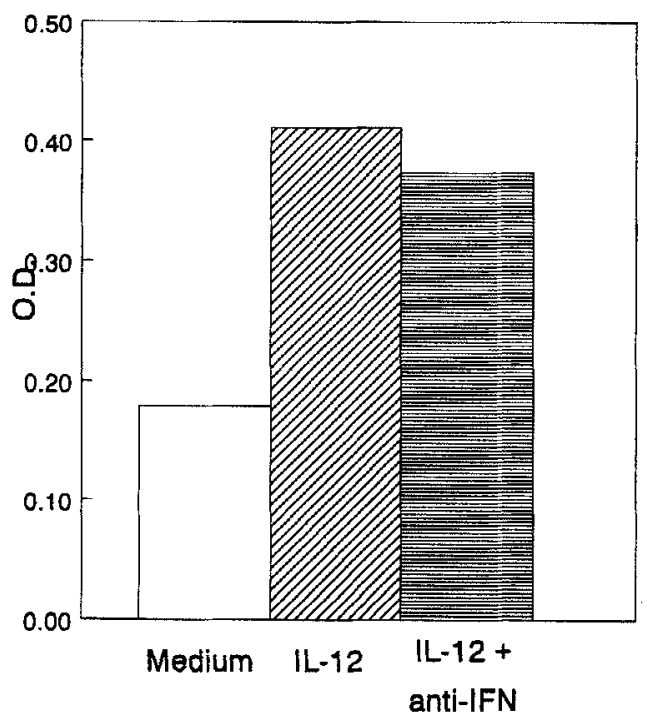

FIGURE 9. IgG2a production in positive cultures from B-cell precursor analyses. Spleen cell cultures were initiated under limiting dilution conditions and replicate sets of supernatant fluids from 10 positive cultures were pooled and assayed in an IgG2a-specific ELISA assay. All cells were incubated with LPS. 


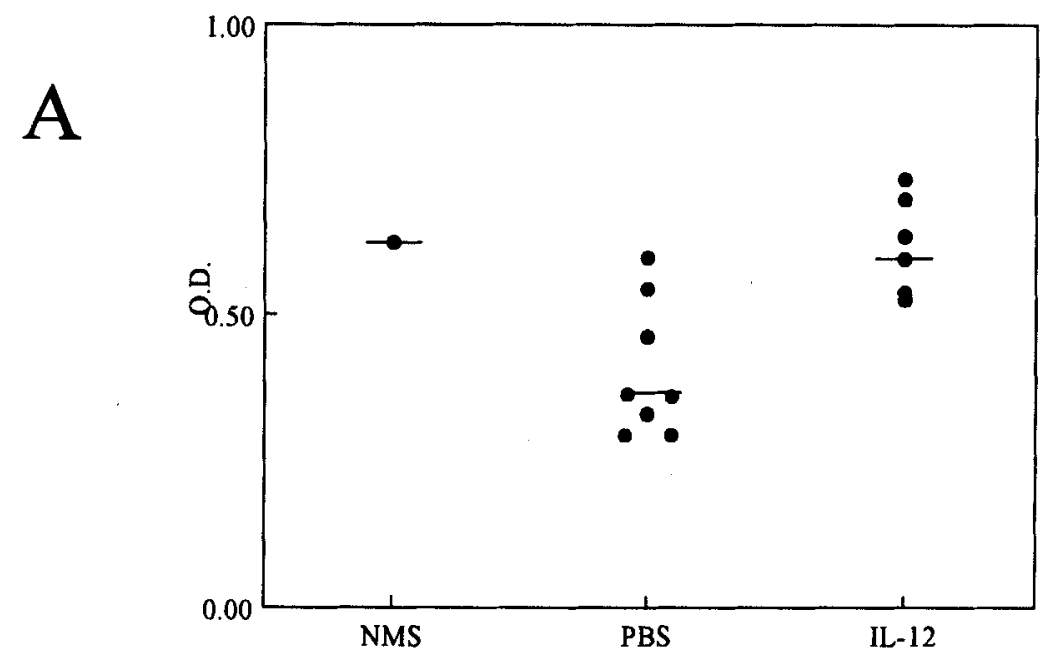

B

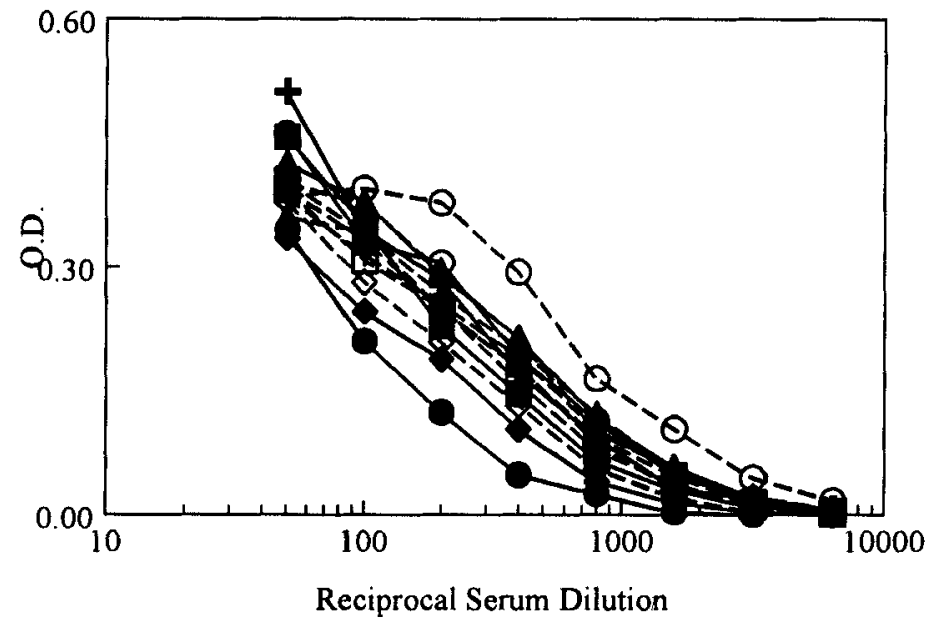

FIGURE 10. Effect of in vivo administration of IL-12 on levels of serum antibodies bearing the T15 idiotype. (A) T15 idjotype levels were measured by inhibition of TEPC 15 myeloma protein binding to the AB1-2 anti-T15 idiotype mAb. Thus, low $O D=$ high idiotype level. Each point represents a 1:50 serum dilution from an individual mouse tested on day 7 after immunization with PC-KLH. By Student's $t$-test, $p<0.01$ between the IL-12 and PBStreated groups. (B) Total anti-PC levels of individual mice. Solid lines, IL-12-treated mice; dashed lines, PBS-treated control mice. There were no significant differences between the two groups. 
TABLE 2. Viable Cell Recovery of Activated Peritoneal B Cells after Culture with IL-12

\begin{tabular}{lcc}
\hline & \multicolumn{2}{c}{ Percent Viable Cell Recovery } \\
\cline { 2 - 3 } Treatment & Experiment 1 & Experiment 2 \\
\hline Medium & 83.0 & 97.0 \\
IL-5 & 81.1 & 97.9 \\
IL-5 + IL-12 & 43.3 & 43.5 \\
\hline
\end{tabular}

NoTE: Viable cell recovery was determined by trypan blue exclusion after culturing peritoneal cells with the indicated cytokines for $24 \mathrm{hr}$ (experiment 1) or $48 \mathrm{hr}$ (experiment 2). No loss of cell recovery was observed after exposure of the cells to IL-12 in the absence of IL-5.

exposure to both IL-12 and antigen, suggesting the generation of two or more signals that act together to reduce peritoneal B-cell levels. Harn and colleagues have similarly noticed a depletion of $\mathrm{B} 1$ cells in the peritoneum of schistosomeinfected mice after IL-12 treatment. ${ }^{25}$

The mechanism for the effects of IL-12 on B1 cells was next investigated by stimulating peritoneal B cells with $\mathrm{IL}-5$ in the presence or absence of IL-12. It was found that in vitro proliferation induced by IL-5 was routinely inhibited by co-incubation with IL-12. To determine whether IL-12 was directly cytotoxic for peritoneal B cells, viable cell recovery was assessed by trypan blue exclusion. The results showed that addition of IL- 12 to activated cells significantly decreased B-cell recovery but had no significant effect on resting cells (TABLE 2). Thus, IL-12 causes suppression of B1 cell function in vivo and appears to lead to cell death in the presence of a stimulatory signal in vitro. The precise mechanisms involved in these effects is currently under investigation and could provide information about the potential use of IL-12 as a therapeutic agent for BI cell disorders such as are observed in autoimmune conditions and chronic lymphocytic leukemia.

\section{DIRECT BINDING OF IL-12 TO B CELLS}

Our studies have shown that many of the in vivo and in vitro effects of IL-12 on $\mathrm{B}$ cells are not mediated by IFN $-\gamma$. Therefore, we examined the possibility that IL-12 interacts directly with B cells. To detect possible binding of IL-12, mouse and human B cells were incubated sequentially with IL-12 followed by biotinylated anti-IL-12 antibody and streptavidin-allophycocyanin. The stained preparations were then tested by flow cytometry. Analysis of murine lymphocytes showed that fresh peritoneal $\mathrm{B}$ cells, but not fresh splenic $\mathrm{B}$ or $\mathrm{T}$ cells, bound murine IL-12, as did spleen cell blasts obtained after LPS stimulation. Human peripheral blood B lymphocytes were also found to bind human IL-12, but only after activation (FIG. 11). A human Burkitt's B-cell lymphoma cell line, SKW6.4, was likewise found to bind IL-12 (FIG. 11). This cell line was previously shown in a preliminary report by $\mathrm{Wu}$ et $a l .{ }^{26}$ to express the $\beta 1$ subunit of the human IL-12 receptor, but these authors were unable to detect direct binding of radiolabeled IL-12. In all of our analyses, positive staining was not obtained if IL-12 was omitted from the procedure or if xenogeneic IL-12 and its respective antibody was used for staining. Furthermore, IL-6 and IL-5 did not competitively inhibit IL-12 binding. 


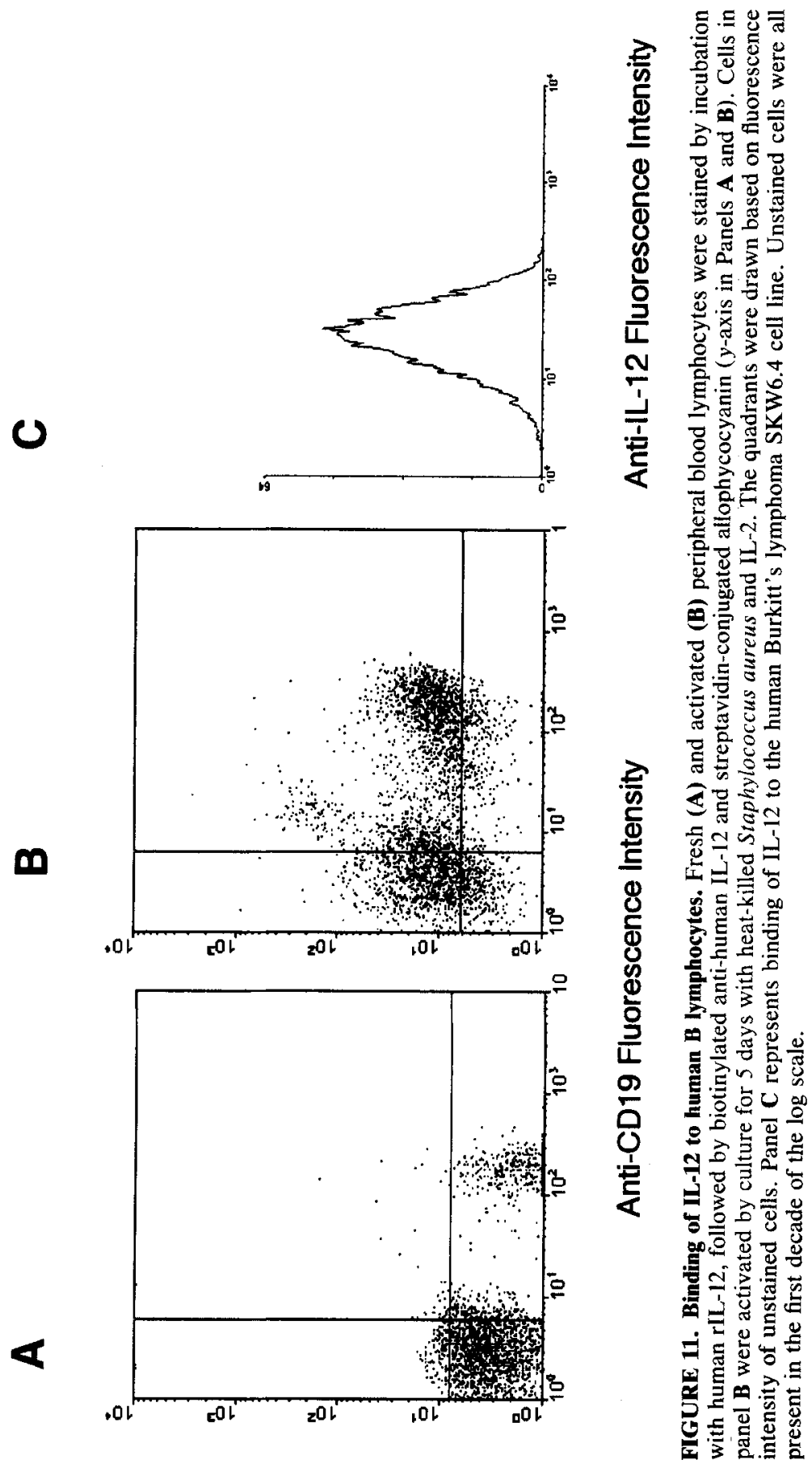


Our results indicate that under the appropriate conditions, both murine and human B cells can be shown to bear an IL-12 receptor. We believe that success in demonstrating binding of IL-12 to B cells is dependent upon (1) suitable activation of $B$ cells to induce significant proliferation; (2) analysis of the appropriate B cell subsets, for example, B1 cells; and (3) use of a highly sensitive flow cy tometry technique such as the one employed here which used the biotin-avidin system and allophycocyanin as a detecting fluorochrome. Further characterization of the $B$ cell IL-12 receptor should provide insight into the reasons for differential responsiveness of $\mathrm{B} 1$ and $\mathrm{B} 2$ cell subsets.

\section{SUMMARY}

We have found that IL-12 treatment of mice leads to long-lasting enhancement in production of most antibody isotypes in conventional B-cell responses. Initial recruitment of new B-cell clones into the response is mediated by IFN- $\gamma$, but subsequent enhancement of Ig secretion appears to be IFN- $\gamma$-independent. We have further found that activated B cells can directly bind IL-12. Taken together, our results suggest a two-step model for the role of IL-12 in enhancement of humoral immunity. Initially, IL-12 induces production of IFN- $\gamma$ from Thl and NK cells. Enough cytokine can be produced from either cell type to then mediate $\gamma 2 \mathrm{a}$ heavy chain isotype switching as well as temporary suppression of IgG1 production. IL-12 further stimulates post-switched cells, including cells producing IgG1, to secrete greatly increased amounts of antibody. This step is not mediated by IFN- $\gamma$ but might be due to direct IL- 12 binding to activated B lymphocytes. Depletion of B 1 cells by IL-12 may further enhance antibody responsiveness since $\mathrm{B} 1$ cells are known to competitively inhibit Ig secretion by conventional B cells. ${ }^{27}$ The end result is that IL-12 causes a generalized upregulation in production of all antibodies and therefore acts as a strong adjuvant for humoral as well as cellular immunity.

\section{REFERENCES}

1. McKnight, A. J., G. J. Zimmer, I. Fogelman, S. F. Wolf \& A. K. Abbas. 1994. J. Immunol. 152: 2172-2179.

2. Morris, S. C., K. B. Madden, J. J. Adamovicz, W. C. Gause, B. R. Hubbard, M. K. Gately \& F. D. Finkelman. 1994. J. Immunol. 152: 1047-1056.

3. Buchanan, J. M., L. A. Vogel, V. H. Van Cleave \& D. W. Metzger. 1995. Int. Immunol. 7: 1519-1528.

4. Germann, T., M. Bongartz, H. Dlugonska, H. Hess, E. Schmitt, L. Kolbe, E. Kolsch, F. J. Podlaski, M. K. Gately \& E. Rude. 1995. Eur. J. Immunol. 25: 823-829.

5. Vezzio, N., M. Gately, M. Kiniwa, C. Y. Wu \& G. Delespesse. 1993. J. Immunol. 150: 61A (Abstr.).

6. Metzger, D. W. \& W. S. Walker. 1988. J. Immunol. Meth. 107: 47-52.

7. Vogel, L. A., E. E. Sercarz \& D. W. Metzger. 1995. Cell. Immunol. 161: 88-97.

8. Snapper, C. M., H. Yamaguchi, R. Sneed, D. Smoot \& J. J. Mond. 1993. J. Immunol. 151: 5251-5260.

9. Layton, J. E., E. S. Vitetra, J. W. Uhr \& P. H. Krammer. 1984. J. Exp. Med. 160: $1850-1863$.

10. Manett, R., F. Gerosa, M. G. Giudizi, R. Biaglotti, P. Parronchi, M. P. Piccinni, S. Sampognaro, E. Maggi, S. Romagnani \& G. Trinchieri. 1994. J. Exp. Med. 179: 1273-1283. 
11. EsSer, C. \& A. Radbruch. 1990. Ann. Rev. Immunol. 8: 717-735.

12. Collins, J. T. \& W. A. Dunnick. 1993. Int. Immunol. 5: 885-891.

13. FörSTER, I. \& K. RAJEWSKY. 1987. Eur. J. Immunol. 17: 521-528.

14. SU, S., M. M. WARD, M. A. APICElla \& R. E. WARD. 1991. J. Immunol. 146: 327-331.

15. Hayakawa, K., R. R. Hardy, M. Honda, L. A. Herzenderg \& A. D. Steinberg. 1984. Proc. Natl. Acad. Sci. USA 81: 2494-2498.

16. Taki, S., M. Schmitt, D. Tarlinton, I. Förster \& K. Rajewsky. 1992. Ann. N.Y. Acad. Sci. 651: 328-335.

17. Wetzel, G. D. 1989. Eur. J. Immunol. 19: 1701-1707.

18. FoY, T. M. \& T. J. Wald SChMidT. 1993. Eur. J. Immunol. 23: 3208-3216.

19. Caligaris-Cappio, F., M. Riva, L. Tesio, M. Schena, G. Gaidano \& L. Bergui. 1989. Blood 73: 1259-1263.

20. Chace, J. H., N. S. Abed, G. L. Adel \& J. S. Cowdery. 1993. Clin. Immunol. Immunopathol. 68: 327-332.

21. Waldschmidt, T. J., F. G. M. Kroese, L. T. Tygrett, D. H. Conrad \& R. G. LYNCH. 1991. Int. Immunol. 3: 305-315.

22. D'Andrea, A., M. Aste-Amezaga, N. M. Valiante, X. Ma, M. Kubin \& G. TrinCHIERI. 1993. J. Exp. Med. 178: 1041-1048.

23. Tripp, C. S., S. F. Wolf \& E. R. Unanue. 1993. Proc. Natl. Acad. Sci. USA 90: $3725-3729$.

24. Masmoudi, H., T. Mota-Santos, F. Huetz, A. Coutinho \& P. A. Cazenave. 1990. Int. Immunol. 2: 515-520.

25. Palanivei, V., D. A. Harn \& J. Sypek. 1994. J. Immunol, 152: 3220 (Abstr.).

26. Wu, C. Y., R. Warrier, D. Carvajal, A. Chua, L. Minetti, P. Mongini, R. Chizzonite, D. Presky, U. Gubler \& M. Gately. 1995. 9th Intl. Congress Immunol.: 299 (Abstr.).

27. Riggs, J. E., R. S. Stowers \& D. E. Mosier. 1990. J. Exp. Med. 172: 475-485. 